\title{
Using critical discourse analysis and the concept of food security to understand pregnant women's nutrition in Aotearoa/New Zealand
}

Briony Raven ${ }^{A}$ MIntDev, BM - Rochelle Stewart-Withers ${ }^{B}, C$ PhD, PGDipNurs, PGDipDevStudies, BN, RCompN

${ }^{\mathrm{A}}$ MidCentral Health, Palmerston North, New Zealand

${ }^{\mathrm{B}}$ Corresponding Author r.r.stewartwithers@massey.ac.nz

${ }^{\mathrm{C}}$ Massey University, Palmerston North, New Zealand

\begin{abstract}
Background: Increasingly, pregnant women in Aotearoa/New Zealand (Aotearoa) are unable to achieve the dietary intakes recommended by the Ministry of Health $(\mathrm{MOH})$. While health professionals express frustration at "being the ambulance at the bottom of the cliff", the continued government response to this public health concern is to "educate women", as per the current mantra of personal responsibility and choice-based rhetoric.
\end{abstract}

Aim: Using critical discourse analysis (CDA), this study examined the discourses regarding nutrition in pregnant women in Aotearoa. Pregnant women's nutrition is further considered within the contexts of food security and empowerment.

Method: In July 2017, using 30 documents from three different platforms - media, government and academia - with a focus on Aotearoa, the first author undertook a CDA.

Findings: Three key messages were identified: firstly, pregnant women, in not being viewed holistically or relationally, are isolated as being solely responsible for nutrition; secondly, women are positioned as naïve recipients, and achieving a healthy pregnancy requires women to be educated and to adhere to complex food guidelines; and lastly, there is an authoritarian use of fear and monitoring to motivate adherence to guidelines. Thus, women are personally responsible for achieving complex, unrealistic and often unaffordable nutritional targets.

Conclusion: The most dominant discourse is one whereby malnutrition is seen as deficit behaviour and thinking by women, and one of self-responsibility, regardless of context. This is very much in keeping with the modus operandi of public health and neo-liberal discourse. We argue, however, this renders silent the fact that malnutrition for some women results more from food insecurity and disempowerment. Midwives need to make audible other less dominant narratives, alongside advocating for woman-centred, policy-based approaches towards nutrition, whereby the underlying drivers of poverty are actively addressed.

Keywords: Aotearoa/New Zealand, critical discourse analysis (CDA), empowerment, feminist, food security, malnutrition, pregnant women

\section{INTRODUCTION}

While Aotearoa/New Zealand (Aotearoa) is widely recognised as a wealthy developed nation, with a growing economy and a high level of food exports, food insecurity is a rising concern (Graham, Stolte, Hodgetts, \& Chamberlain, 2016; Pollard \& Booth, 2019; Schlichting, Hashemi \& Grant, 2019). Most recent available data highlight that $7.3 \%$ of Aotearoa households experience food insecurity (Graham \& Jackson, 2017). Food security data in Aotearoa are similar to international data, with more women food insecure compared to men (Broussard, 2019; de Schutter, 2016). The National Council of Women of New Zealand (2019) has identified poverty as the major economic issue facing many women in Aotearoa, with women consistently earning less than men. Hence women living in poverty who are pregnant face greater concerns and can become more vulnerable economically, socially and physically.
The importance of nutrition during pregnancy is well recognised, with pregnancy being a time when health inequities can be exacerbated if malnutrition is transmitted to the next generation (Wall et al., 2016). The health and wellbeing of the woman and her baby can be affected by poor nutrition, specifically micro-nutrient deficiencies such as that of iron (Greig, Patterson, Collins, \& Chalmers, 2013). Problematically, "most pregnant women ...do not adhere to nutritional guidelines in pregnancy, with only 3\% meeting the recommendations for all four food groups" (Morton et al., 2014, p.1).

Previous government responses have sought to address the issue by targeting perceived educational or individual deficits through the mantra of personal responsibility and choice-based rhetoric. Yet this is failing to improve outcomes (Davies et al., 2016; Growing Up in New Zealand, 2014; Wall et al., 2016). While health professionals express frustration at "being the ambulance at the 
bottom of the cliff", the continued response to this public health concern, in line with deficit thinking, is to "educate women". To view pregnant women's poor nutrition as an individual deficit and/or lack of knowledge is too simplistic. If these issues are to be truly addressed then a more nuanced understanding of reasons for women's malnutrition during pregnancy is required. We argue the concepts of food security and empowerment render visible some of the nuances.

Using a critical discourse analysis (CDA), this study examined the discourses regarding nutrition in pregnant women in Aotearoa, within the contexts of food security and empowerment. In this study, a discourse is defined as "the social process in which texts are embedded" (Locke, 2004, p.14). An example of this in healthcare is the construction of dominant health messages, hospital policies and health practices which make up a discourse within powerful institutions such as hospitals and professional colleges, and which directly affect health outcomes for women and families, such as immunisation. Some authors argue that fear-based messages linking "unhealthy" food choices with laziness, obesity and chronic ill health are used to motivate people into making "healthy" food choices (Dodds \& Chamberlain, 2017). The application of CDA therefore looks to expose power relationships, assumptions and bias (O'Leary, 2009).

This paper firstly explains what the concept of food security entails; secondly, it discusses in more detail malnutrition, specifically the concept of hidden hunger, and considers this in relation to women and pregnant women; thirdly, it explores what is meant by empowerment; fourthly, it explains the CDA process before presenting our findings; and finally, it draws some broad conclusions and explains how these relate to midwifery.

\section{Conceptualising food security}

The term "food security" was first used at the 1974 World Food Conference. The Food and Agriculture Organization of the United Nations (FAO) defines this as:

...food security at the individual, household, national,
regional and global scale is achieved when all people, at all
times, have physical and economic access to sufficient, safe
and nutritious food to meet their dietary needs and food
preferences for an active and healthy life (FAO, 1996, p.1).

This definition is the most useful and frequently cited. It specifies that food must be of a quality and quantity that allows everyone to meet their dietary needs and food preferences. A lack of food security leads to hunger, hidden or obvious (FAO, 1996; 2008). Further to meeting the definition of food security, a food secure context must also align with the four pillars of food security (Figure 1; FAO, 2008; Tiffin, 2014).

Therefore, a context which is food secure is one where there is sufficient availability of food, there is sufficient access to sufficient quantity and quality of foods, food is appropriately and safely used, and lastly, these pillars are stable over time and seasons. This framework provides a way of analysing a given context, and can reveal underlying cultural, political and economic factors which influence the four pillars of food security. This analysis can further reflect the distribution of access to power; for example, purchasing power, political status, and capacity. Food insecurity within a food secure population such as Aotearoa is likely to be caused by inequity of access to sufficient and appropriate foods for vulnerable groups. Uncorrected food insecurity manifests initially as malnutrition for pockets of the population.

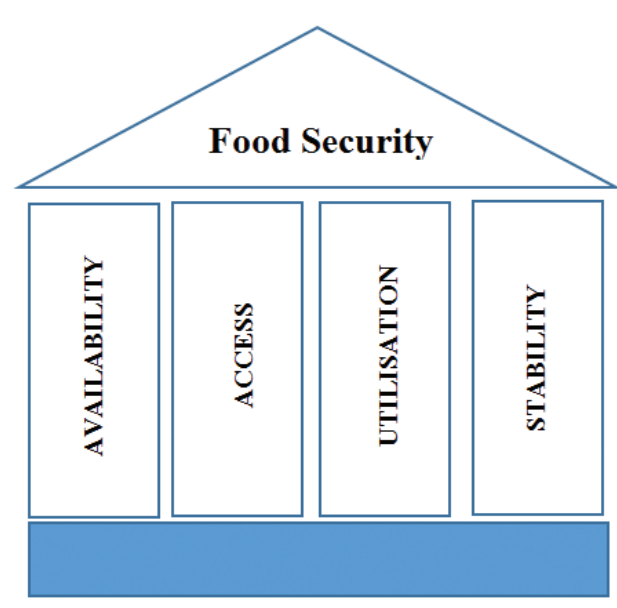

Figure 1. Food security framework - four pillars of food security

\section{Disempowering discourses: Malnutrition, hidden hunger and women}

\section{Malnutrition and hidden hunger}

Malnutrition can be understood as either over or under nutrition and is caused by insufficient foods as well as diets based on the wrong type or quantities of food (Shetty, 2008). Therefore, both stuntedness and obesity are forms of malnutrition. A more specific form of malnutrition is hidden hunger (James \& Rigby, 2012; World Health Organization [WHO], 2006). Named because of its high impact but lack of visibility, hidden hunger refers to a form of malnutrition connected to a calorie rich diet but with deficiencies of micro-nutrients such as iodine, iron and vitamin A (James \& Rigby, 2012; Kimura, 2013). Hidden hunger hence reflects low quality, high energy diets.

Hidden hunger is thought to impact up to 2 billion people (Wendelbo, 2018; WHO, 2006), with implications for mortality and morbidity (Shetty, 2008); yet, it remains under considered due to the continued focus on conspicuous hunger, calorie consumption and quantity of foods. Individuals experiencing hidden hunger are usually food insecure due to poor access (Tiffin, 2014). An example of this was during the world food crisis in 2007 when prices for basic foodstuffs rose drastically, directly affecting those living in poverty. Studies of this food crisis provide evidence of a form of malnutrition in which calorie consumption remained constant but as poverty grew, dietary diversity was reduced and child malnutrition increased (Headey, Oliver, \& Trinh Tan, 2014). The consumption of fresh fruit and vegetables, for example, which is directly related to socio-economic status, is likely to decrease in food insecure contexts (Parnell, 2012).

At the global level, patterns of food production, supply and access have had a widespread impact on how people value, consume and conceptualise food (Tiffin, 2014). One example of this is "the nutrition transition". The nutrition transition describes a global shift where increased prosperity and urbanisation have led to a transition from traditional foods and physically demanding lifestyles to low-cost foods and sedentary lifestyles (Jha, Gaiha, \& Deolalikar, 2014; Tiffin, 2014). The rise of non-communicable diseases (NCDs), such as diabetes and cardiovascular disease, is linked to the nutrition transition, with increased levels of malnutrition caused by the overconsumption of energy dense foods (Tiffin, 2014). Now the majority of deaths globally are caused by 
NCDs, with a sub-optimal diet as a key risk factor (Smith \& Signal, 2009). However, not all individuals grappling with the drivers of the nutrition transition are experiencing malnourishment. Individuals who can retain a high level of purchasing power and who are empowered within their community and home environments can withstand fluctuations in global food prices to achieve adequate nutrition access.

One of the most common forms of malnutrition faced by pregnant women is "hidden hunger", for example, iron deficiency anaemia (IDA). IDA in Aotearoa is considered to be mild, affecting $5-19 \%$ of pregnant women (WHO, 2008). While seen as mild, it is of significance when compared to global figures (Ferguson et al., 2001; Ministry of Health, MOH, 2008a). The Aotearoa national nutrition surveys have also found a disturbing trend, with ferritin (iron stores) deficiency prevalence among girls and women over 15 years of age more than doubling from 3\% in 1997 to $7 \%$ in 2008/2009. FAO, International Fund for Agricultural Development, United Nations Children's Fund and WHO (2017) further highlight the worldwide prevalence of anaemia among women of reproductive age, 15-49 years, which was $11.6 \%$ in 2016. This is problematic as even a mild level of iron deficiency impacts on women's cognitive function, quality of life and most importantly, pregnancy and birth (Ferguson et al., 2001; Gibson, Heath, \& Ferguson, 2002; MOH, 2008a).

The response to micro-nutrient deficiencies in Aotearoa has been to resort to dietary supplementation; however, this "nutritionalist approach" is unlikely to improve overall wellbeing, nor does it empower women to gain access to an appropriate and adequate diet (Davies et al., 2016). Supplementation does little to address the complex causes of malnutrition such as food insecurity (Gibson et al., 2002).

Obesity, another form of malnutrition, is strongly linked to an obesogenic environment, where culture, employment opportunities, the local housing market, and access to transport and healthy food impact on food accessibility and choices (Pearce, Richardson, Mitchell, \& Short, 2011). Obesity in Aotearoa women is on the rise, from $20 \%$ of the population in 1997 to $27 \%$ in 2008 (MOH, 2008a), and 30.5\% in 2014 (FAO et al., 2017). In South Auckland local obstetric guidelines have had to amend the application of the national referral guidelines due to the pressure on secondary care services. High numbers of obese and morbidly obese pregnant women are now considered the "new normal", and are regularly cared for within primary care services (Counties Manukau District Health Board, 2013).

\section{Women and hidden hunger}

Women are normally able to maintain adequate calorific intake but when in crisis their ability to retain a high quality and nutritious diet, which is especially important in pregnancy, reduces (Gibson et al., 2002). As levels of crises are heightened, due to globalisation, for example, there is increased pressure for women to participate within productive and formal roles to generate income. But as women generally are paid less, they cannot buy as much as men. This exposes female workers to a greater risk of food insecurity and to the poverty nexus, with women who experience malnutrition being even less able to generate income due to reduced cognitive ability, productivity and capacity caused by micro-nutrient deficiencies (Horton \& Ross, 2003).

\section{Women, food and the household/family unit}

Women are at risk in times of crisis, both by social and cultural norms which discriminate against them and by their own actions, as women may allocate more nutritious foods to children and, in times of stress, will act as "shock absorbers", restricting their own dietary intake (Brody, 2015; Martin \& Lippert, 2012). There is some evidence to suggest women are shielding men from the effects of food insecurity in Aotearoa by prioritising nutrient rich and more expensive foods for men and children, and at times even going without (Graham et al., 2016; Martin \& Lippert, 2012).

Figure 2 outlines the consequences of household food insecurity and conceptualises how malnutrition affects women. An increased consumption of high energy foods, such as bread or simple carbohydrates, results in reduced nutrient intake and increased levels of obesity for women in households which are food insecure (Martin \& Lippert, 2012; Papan \& Clow, 2015). This partially explains dietary intake data from developed countries with respect to pregnant women, which revealed they did not reach recommended levels for folate, iron, or vitamin $\mathrm{D}$, despite increased energy intakes reported (Blumfield, Hure, MacdonaldWicks, Smith, \& Collins, 2013). This interestingly also supports the claim that women in both developed and developing nations are more vulnerable to food insecurity and, increasingly in both realms, more women are obese than men.

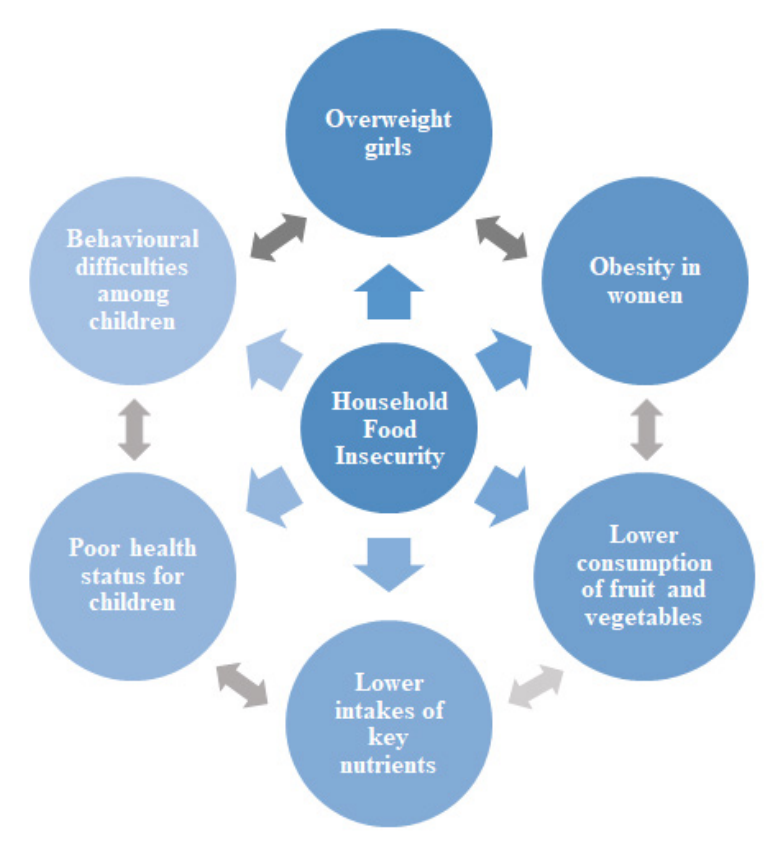

Figure 2. Emerging evidence of consequences of household food insecurity

\section{Theoretical underpinnings: Empowerment and the food security nexus}

Empowerment involves three elements: (1) the power within that is, changes in how women view themselves; (2) the power to impose change more broadly within society; and (3) the power to join with other women and men to reinforce the momentum for change (Kabeer, 2010). Table 1 conceptualises the food security framework discussed earlier with women's empowerment. Applying the concept of food security places the focus on selfempowerment as the key to gender equity, where women articulate their own needs rather than having them predicted and met on their behalf. It investigates divergence, diversity and complexity, "to pull apart" women's positioning in relation to food security.

The food security literature has developed over time to conceptualise food security as reflecting social, political, economic 
and cultural factors. Countries like Aotearoa face challenges with responding to food insecurity because it is often poorly monitored and remains, until recently, largely unacknowledged. There are numerous threats to the global food production systems, requiring improved analysis and investigation in order to provide warnings about growing food crises in both developed and developing countries (Headey et al., 2014). Moreover, global factors, such as the nutrition transition described prior, have had different impacts on individuals within the same household based on gender and age (Jha et al., 2014). This indicates that power inequalities can increase food insecurity at the household level. Through the investigating of "hidden pathways" which disempower women from attaining food security, the prevalence of "hidden hunger" becomes more evident. A focus on power analysis is hence likely to be the more effective pathway to understanding food and nutrition security for pregnant women.

Table 1. An empowerment framework related to food security

\begin{tabular}{|c|c|c|c|}
\hline & Power within: & Power to: & Power with: \\
\hline Availability & $\begin{array}{l}\text { Women recognise } \\
\text { their right to } \\
\text { sufficient quality } \\
\text { and quantity of } \\
\text { food. }\end{array}$ & $\begin{array}{l}\text { Women can } \\
\text { meet their } \\
\text { food needs } \\
\text { for sufficient } \\
\text { quality and } \\
\text { quantity of } \\
\text { food. }\end{array}$ & $\begin{array}{l}\text { Women can } \\
\text { make change } \\
\text { with others to } \\
\text { improve the } \\
\text { availability of } \\
\text { food within their } \\
\text { communities } \\
\text { nationally and } \\
\text { globally. }\end{array}$ \\
\hline Access & $\begin{array}{l}\text { Women } \\
\text { understand how } \\
\text { their wellbeing } \\
\text { is connected to } \\
\text { adequate access } \\
\text { to food. }\end{array}$ & $\begin{array}{l}\text { Women can } \\
\text { negotiate } \\
\text { adequate } \\
\text { food access } \\
\text { within their } \\
\text { families and } \\
\text { communities. }\end{array}$ & $\begin{array}{l}\text { Women can } \\
\text { make change } \\
\text { with others to } \\
\text { respond to } \\
\text { factors which } \\
\text { affect their } \\
\text { access to food. }\end{array}$ \\
\hline Utility & $\begin{array}{l}\text { Women are } \\
\text { confident and } \\
\text { able to utilise } \\
\text { food to meet their } \\
\text { needs. }\end{array}$ & $\begin{array}{l}\text { Women have } \\
\text { resources to } \\
\text { develop their } \\
\text { knowledge } \\
\text { around food } \\
\text { utility. }\end{array}$ & $\begin{array}{l}\text { Women can } \\
\text { work with others } \\
\text { to improve food } \\
\text { utility in their } \\
\text { communities. }\end{array}$ \\
\hline Stability & $\begin{array}{l}\text { Women possess } \\
\text { self-confidence } \\
\text { and adequate } \\
\text { self-esteem to } \\
\text { recognise and } \\
\text { voice concerns. }\end{array}$ & $\begin{array}{l}\text { Women can } \\
\text { counter threats } \\
\text { to food security } \\
\text { in the short, } \\
\text { medium and } \\
\text { long term. }\end{array}$ & $\begin{array}{l}\text { Women can } \\
\text { work with others } \\
\text { to respond to } \\
\text { the food stability } \\
\text { threats in their } \\
\text { community. }\end{array}$ \\
\hline
\end{tabular}

\section{METHODOLOGY: A CRITICAL DISCOURSE ANALYSIS}

CDA explores the relationship between discourse and power to reveal abuses of power and systemic inequalities in operation across society (Weiss \& Wodak, 2002). It assumes that certain groups are privileged over others and, if not sufficiently critical, CDA itself may be implicated in the reproduction of forms of oppression (Locke, 2004). CDA theorists therefore aim to disseminate a critical awareness of language as a factor in domination (Fairclough, 1995). Particularly in health settings, discourse and narratives have powerful impacts. As noted by Pollard and Booth (2019), how we define and frame issues shapes the response. Problematically, this can stigmatise, stereotype and reinforce disadvantage. The dualist nature of modern health systems is a prime example of this - the problem is often the patient or the disease, with the solution being the doctor or medicine. This discourse operates in a reciprocal relationship with social institutions and structures, which replicate the framing of the discourse throughout society. This impacts on all of us but inequitably impacts on "othered" groups, especially indigenous people and people living in poverty - those positioned at the margins. Weiss and Wodak further simplify this explanation by labelling discourse used in speech and text as a "social practice" which has a "dialectical relationship" with institutions and social structures (Weiss \& Wodak, 2002, p.13).

The social practice within text can be analysed to reveal assumptions and bias by:

1. Clarifying the theoretical assumptions within a text;

2. Identifying conceptual tools such as linguistics to reveal connections with discourse and social structures or outcomes;

3. Defining categories or "analytical concepts" which explain specific phenomena (Weiss \& Wodak, 2002, p.13).

\section{Data collection}

For this paper, a CDA process was developed drawing on works of various significant authors (Fairclough, 1995, 2003; Janks, 1997; Locke, 2004; O'Leary, 2009; Weiss \& Wodak, 2002). To practically apply the goals of CDA, four key questions of the texts were asked:

1. How is the text positioned?

2. Whose interests are served by this positioning?

3. Whose interests are negated?

4. What are the consequences of this positioning? (Janks, 1997).

Thirty articles were selected for analysis, consisting of 10 media, 10 government and 10 academic articles (Table 2).

\section{Table 2. Document selection process}

\section{Academic articles}

Search terms through Massey Discover platform: "Tl (New Zealand or Otago or Auckland) AND TI (Pregnant or pregnancy) AND SU (nutrition or food or food security or malnutrition or nutrients or deficiency diet or eating)"

Limited to: $\quad$ First 10 articles (order of relevance)

'Folate knowledge and consumer behaviour among pregnant New Zealand women prior to the potential introduction of mandatory fortification' - unable to find in English

Limit to academic articles

Limit to 2007-2017

\section{Media articles}

Search terms through google.co.nz news platform: "nutrition OR diet $O R$ malnutrition $O R$ food OR security $O R$ nutrients $O R$ supplementation OR eating" + "pregnancy"

Limited to: $\quad$ Most relevant - celebrity, personal stories omitted First 10 articles

Within New Zealand region only, under advance search settings

\section{Government articles}

Search terms through google.co.nz - site: govt.nz: "pregnancy" + "nutrition $O R$ diet $O R$ malnutrition $O R$ food $O R$ security $O R$ nutrients $O R$ supplementation OR eating"

Limited to:

First 10 articles

Omitting repeats

Omitted anything older than 2007

Analysis required a two-step approach: firstly, a detailed analysis of sentence structures and words (specifically nouns and verbs), followed by a wider approach looking at themes (Fairclough, 1995). The goal of this analysis was to reveal the assumptions that formed the ideological basis within the text, specifically: 
1. Existential assumptions about what exists;

2. Propositional assumptions about what is, can, or will be; and

3. Value assumptions about what is good or desirable (Fairclough, 2003, p.55).

Secondly, to reveal the ideological basis of the articles analysed, Janks's questions were reframed to work within the limitations of this project:

1. What is the central theme in positioning the text? What is the "problem" framed as?

2. Who is the text directed to? Who is assigned responsibility for the "problem"? (Janks, 1997).

To answer these questions, analysis further looked at the use of pronouns, commonly repeated words and phrases, as well as concepts and words omitted. Specific text analysis tools revealed patterns and themes in the text. These key questions were built on to develop a table summarising Fairclough's, Janks's and Locke's textual analysis tools (Table 3).

\begin{tabular}{ll} 
Table 3. Text analysis process \\
Step 1 & $\begin{array}{l}\text { Identification of patterns, key words repeated which set up } \\
\text { a complex web of interconnectedness across the discourse } \\
\text { (Janks, 1997; Locke, 2004). }\end{array}$ \\
\hline Step 2 & $\begin{array}{l}\text { Identify how the social identity and relationships have been } \\
\text { constructed (Locke, 2004). }\end{array}$ \\
\hline Step 3 & $\begin{array}{l}\text { Analyse pronouns which stitch together the text and its } \\
\text { meaning. This can identify who the "problem" is directed to } \\
\text { (Locke, 2004). }\end{array}$ \\
\hline Step 4 & $\begin{array}{l}\text { Assess the force of the text and its nature, as evidence of } \\
\text { social and power relations (Locke, 2004). }\end{array}$ \\
\hline Step 5 & $\begin{array}{l}\text { Identify the marginalised or hidden view through both the } \\
\text { use of the words as well as the suppression of their opposites } \\
\text { (O'Leary, 2009). }\end{array}$ \\
\hline Step 6 & $\begin{array}{l}\text { Identify which voices are included and which voices are } \\
\text { significantly excluded? How are voices textured in relation } \\
\text { to the authoritative voice? (Fairclough, 2003). }\end{array}$ \\
\hline Step 7 & $\begin{array}{l}\text { Identify ideological assumptions; what do authors commit } \\
\text { themselves to in terms of truth? What is an irrational } \\
\text { assumption within the text? (Fairclough, 2003) }\end{array}$ \\
\hline
\end{tabular}

Using the above process, and noting both consistencies and inconsistencies across the text, the first author reviewed each document. Sentences, which summarised a key message or the key findings of the document, as well as key words, which identified who the writing was directed at and how this group had been conceptualised, were marked. Distinct words and concepts were repeated often throughout the body of work. This repetition of common themes and words exposed a discourse which is surprisingly similar across the realms, namely, "pregnant women are singularly responsible for ensuring adequate nutrition". This analysis was further developed by using the quantitative MAXQDA software programme to generate word clouds based on the frequency of word usage (Figure 3).

A further analysis of the texts looked at the most common word combinations of three words which had three or more letters. Across all 30 documents, "nutrition guidelines for" was the most highly ranked and reflects the dominance of adherence to the nutritional guidelines as a key phrase within the text.

In the 10 media documents "pregnancy" and "pregnant" again feature strongly. However, words such as "risk", "avoid" and "should" feature more prominently in the media texts. This also concurs with the most common word combination in these documents which is "the risk of"; this reinforces the use of fear to motivate women to adhere to nutritional guidelines. activity advice age alcohol associated birth birthweight breast diet

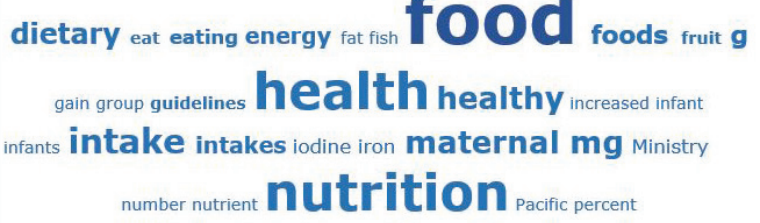

pregnancy pregnant

recommended $\mathbf{r i s k}$ servings should status vegetables vitamin weight WOmen

Figure 3. Word cloud: all documents

In contrast, "pregnancy" is the dominant word for the academic texts, with "women" used far less often. As well as this, "dietary", "intake", "mg" and "g" also feature strongly. "The Ministry of" is the most frequent word combination followed by "College of Midwives", demonstrating the dominance of these institutions as authorities within the academic texts.

The government documents closely reflect the analysis of the full body of documents with "women" again being dominant as well as "food". The most frequent word combination is "nutrition guidelines for", again reflecting the broader body of texts.

Finally, because this was a study of text and discourses, ethics review and approval were not required. Regardless, ethics and research integrity remain important in terms of ensuring the research is considered trustworthy due to the soundness of the methods and the honesty and accuracy in terms of presenting the findings (O'Leary, 2009). Input from internal academics, as well as consideration of the early findings by an academic outside the project, further contributed to the rigour and trustworthiness of the study.

\section{FINDINGS}

Reoccurring across the documents were three key messages:

- $\quad$ Pregnant women are singularly responsible for ensuring adequate nutrition.

- A healthy pregnancy requires women to be educated to adhere to complex food guidelines.

- Fear and monitoring of women are used to motivate adherence.

A fourth message can also be found, that is the problem of access to quality foods for pregnant women (Boland \& Gibbons, 2009; MOH, 2008b; Yin, Dixon, Paterson, \& Campbell, 2014), and, while it is still concluded that women require further education to achieve compliance with food guidelines, there is some recognition about lack of finances and other resources as barriers (Yin et al., 2014). This presents a tension in that while health professionals recognise that women may be unable to achieve adherence, there remains an expectation that women will try to comply.

In terms of separating out results, the media articles consistently sensationalise and often use inflammatory and fear provoking language such as "diet overkill", "can harm a growing baby" and "putting... their babies at risk" to engender an audience (Australian Associated Press, 2011; Tasker, 2017). In three of the media articles, women themselves are quoted discussing both 
their desires and difficulties during the pregnancy, advising other women as to how they should manage expectations, admitting "overindulging in foods" and "being consumed with worry and anxiety” (Essentialbaby.com.au, 2015; Hartley, 2017). There is also contradictory information which generates uncertainty and drama, creating a "confusing maze of dietary restrictions" which the media builds on to generate cheaply produced material (Corderoy, 2017). This increases the stress on women navigating a dramatised discourse.

The government material falls into two fields. In the first field a clear health promotion agenda is directed at pregnant women, to clarify and detail a complex set of nutritional guidelines. The second field is to inform policy and health agendas by detailing key research which emphasises the importance of appropriate nutrition for the wellbeing of the pregnancy and the infant. This literature argues the need to educate pregnant women to adhere to guidelines with the government positioned as the key authority about a complex and technical "problem". Addressing pregnant women as isolated and autonomous individuals, these guidelines are complex, only focus on pregnant women, and are designed to promote adherence.

The academic texts are the most diverse. Drawing from a range of academic and professional disciplines from midwifery to nutrition, the academic sources look at malnutrition in pregnancy from a variety of perspectives. While each research article has an agenda and a perspective on "the problem", they still ascribe to the three key messages identified above. The academic nature of the work attributes importance to high quality data, yet only one included the voices of pregnant women in the text, with one further text investigating women's knowledge and beliefs about nutrition though a questionnaire (Paterson, Hay-Smith, \& Treharne, 2016). This lack of engagement with pregnant women's voices indicates that the authority to describe "the problem" rests with researchers (Okesene-Gafa, Chelimo, Chua, Henning, \& McCowan, 2016).

Throughout the literature, there is a limited discussion of food security despite the evidence showing concerns for women in Aotearoa over the last ten years $(\mathrm{MOH}, 2012)$. Malnutrition in pregnancy is consistently problematised as the responsibility of individual pregnant women rather than a national public health concern. This framing persists despite a uniform agreement across the texts that malnutrition in pregnancy is rising to a concerning level, with the impacts on infants extensively detailed. There is also a consensus that the current response is failing to improve women's wellbeing. These messages are arranged now as themes for the purpose of a more detailed discussion.

\section{DISCUSSION}

\section{Theme one: Framing identities of women who are pregnant}

Most of the articles refer to women as "pregnant women" with the pregnancy itself denoting their status. Other subjects in the texts are described as "mums to be "or "pregnant Kiwis", indicating that women are waiting to gain status as mothers and with the pregnancy itself the key identity in women's lives (Nakhle, 2015; Tasker, 2017). In contrast to this, several academic articles describe the subject as women who are pregnant or just women, indicating that womanhood is the primary identity of the subjects, with the pregnancy existing alongside this identity (Boland \& Gibbons, 2009; Okesene-Gafa et al., 2016; Wall et al., 2016; Yin et al., 2014). In three of the titles of the academic texts, the subjects are maternal diet or the pregnancy, thereby excluding women altogether as subjects (Boland \& Gibbons, 2009; Morton et al., 2014; Wall et al., 2016). In the media and government texts only four reference pregnant women as the subject in the title, with the 16 other texts deferring to the pregnancy itself as the subject of the article (Corderoy, 2017; MOH, 2008b, 2017).

This dominant focus on the pregnancy as the key subject rather than women or pregnant women is also signalled by the images which accompany the texts. Out of 10 articles which include photographs of pregnant women, $80 \%$ have an image which is cropped to focus only on the pregnant uterus. Again this indicates that the subject of the text is the pregnancy itself as independent from women as whole citizens functioning within society. In contrast to this, two resources from the $\mathrm{MOH}$ show "whole women" pursuing activities with other women indicating they perceive women as functional within a society $(\mathrm{MOH}, 2008 \mathrm{~b}$, 2017). This suggests that the current discourse frames the primary identity of pregnant women in reference to the pregnancy rather than as fully participating and active women in society.

\section{Theme two: A healthy pregnancy requires adherence to guidelines}

Theme two has been identified in answer to the CDA text analysis question: What is the central theme in positioning the text? What is the "problem" framed as? Many of the texts prescribe the nutritional and food safety requirements women need to adhere to, to ensure a healthy pregnancy. These prescriptions include specific instructions for women who must "limit" or "avoid" unhealthy or unsafe foods (Food Standards Australia and New Zealand, 2016). The government and media texts discuss the many complex and varied requirements to achieve health. This advice is technical and specific down to the consumption of grams of micro and macro nutrients per day. Food is divided into foods to avoid, and foods which are best or healthier. This breakdown of food into grams, and good food versus bad food creates a rule book which abstracts the concept of health and nutrition into a calculation requiring management. Women's enjoyment of meals, the taste of food and any spiritual or cultural meaning of foods are not emphasised as contributing to health and wellbeing.

The $\mathrm{MOH}$ nutritional guidelines are detailed in an 8-page booklet and include many specific instructions: for example, women should "eat ... at least four servings of vegetables and two servings of fruit. If you do choose juice or dried fruit have no more than one serving per day" (MOH, 2017, p.1). Examples of what make up a serving of vegetables and fruit are detailed further. Perhaps the most confusing message is around eating fish. Women are advised variously of the health benefits of seafood consumption, of the risk of high levels of mercury, to limit consumption of fish with potentially high levels of mercury, to have a very limited consumption of other fish and that the recommendations may change over time $(\mathrm{MOH}, 2017)$. These instructions require a high level of literacy, comprehension, and education to follow and incorporate into everyday life.

Pregnant women as passive recipients of nutritional messages As previously discussed, pregnant women's identity as women and their voices within the texts are limited. The focus is instead on the "voices of experts". In the media articles, the authority is often dieticians who justify their expert status by describing the complexities of eating the right foods during pregnancy. In the academic texts, researchers analyse pregnant women's food frequency questionnaires and blood tests rather than discussing with women their knowledge and concerns around food and nutrition. These experts then describe the "problem", as well as solutions based on these measures. This said, since completing this study, along with work by Yin et al. (2014), publications have 
emerged where women's voices are included, for example, Pullon et al. (2019).

Several texts describe women as ignoring the guidelines, suggesting that they should be listening and compliant, rather than seeking active participation (Corderoy, 2017). Many of the texts recognise the failure of these nutritional messages and, in response, they call for "women to be weighed more often", or suggest "women need to be given more information" and specific groups of women need to be targeted more effectively (Tasker, 2017; Wall et al., 2016, p.1). Several texts hold women to account for "being mistaken over healthy diet" and for erroneous beliefs around "eating for two" (Corderoy, 2017; Hartley, 2017). This framing posits that the authority is the researcher or the health professional who educates women as to what they should/should not eat, with women failing to follow the guidelines. These are examples of how the discourse dictates acceptable behaviour to women rather than supporting them to improve diets during pregnancy.

\section{Failure to adhere to guidelines leads to poor outcomes}

Most of the documents conclude that pregnant women's failure to adhere to these guidelines is leading to poor outcomes. Thus, they define women's behaviour as "the problem". On the other hand some academic texts posit that "the problem" is in meeting the extra nutritional demands of the pregnancy with adherence to the nutritional guidelines thus a necessity (Davies et al., 2016; Growing up in New Zealand, 2014). It seems that women are targeted as both the cause of the problem as well as the solution to the problem. If a failure to adhere to nutritional guidelines is the problem, then the solution is to work harder to get pregnant women to follow the guidelines. The literature positions pregnant women as requiring specific education around nutrition $(\mathrm{MOH}$, 2008b, 2017). Conversely, many of the documents position education as the solution but also recognise its failure to create lifestyle change (Davies et al., 2016).

\section{Theme three: Fear and monitoring to motivate adherence}

The repetition of the word "safe" across most of the media documents suggests an action is required to ensure safety is maintained. The recommended action is always adherence to the guidelines. Specific instructions to women are focussed predominantly on the risk of harm to the baby and on being "on the safe side" (Auckland District Health Board National Women's Health, 2017; Essentialbaby.com.au, 2015; Hartley, 2017; Nakhle, 2015). There is no comment on the joy of motherhood or pregnancy or of the amazing achievement of women who can conceive, grow, and nurture healthy babies. There is no positive story where women achieve success in their pregnancies - even though most pregnancies have positive outcomes for women and their babies. Two articles have women specifically discussing their fears and their concerns in an emotional and dramatic discussion. One woman states "but more than anything I worried about the food I was putting into my mouth"; this emphasises a risk and fear based approach to healthy eating and overly dramatises the risks of food safety and nutrition (Essentialbaby.com.au, 2015; Hartley, 2017). In this discourse, the pregnancy is an abnormal life event which needs to be managed and becomes an issue of self-control and discipline. Women can no longer enjoy certain foods and should instead adhere, monitor and avoid or limit their eating (Australian Associated Press, 2011). The shifting and confusing narratives across the texts about what is permissible are emphasised and generate more fear with women doing something they are not really meant to (Nakhle, 2015).
There is also a theme of monitoring the ability of women to adhere to guidelines. Pregnant women described feeling watched and having their decisions judged by people in society with comments like: "urgh look at her", "you'd get away with it" and an example of being told off by a midwife for being "naughty" (Paterson et al., 2016, p.8). In one article a spokeswoman for the Dietitians Association of Australia admits that women "need to be very, very organised, and well-planned or have a strict diet" to meet the guidelines; she admits nobody in Australia is really meeting these guidelines but retains a high level of expectation that pregnant women will be able to conform to them (Corderoy, 2017). The academic texts focus on monitoring women's nutritional status but only two explore with women their thoughts and beliefs around nutrition, indicating the importance of monitoring, but not talking with, women (Okesene-Gafa et al., 2016; Paterson et al., 2016).

\section{Overarching phrase: "Walking the tightrope"}

A discourse is "the social process in which texts are embedded"; thus discourse is both establishing and creating meaning in the world (Locke, 2004, p.14). CDA deepens this analysis by also revealing power structures which are being constructed and replicated (Fairclough, 1995). The phrase, "walking the tightrope" describes a precarious situation that demands careful and considered behaviour regardless of socio-economic circumstances. This grand theme brings together the three main messages found in the texts and reveals the power structures which position pregnant women in a vulnerable space of both being the target of an impossible expectation as well as not having a clear role or voice in responding to this situation. The issue is primarily framed as one of personal responsibility and adherence to guidelines. Yet this response fails to acknowledge the lack of access to appropriate resources for many families to live healthy lives (Graham et al., 2016), It also remains in keeping with a middle-class "nutritionist approach" which judges those living with food insecurity to be making poor food choices due to a lack of nutritional knowledge (Graham et al., 2016). Feeding a family with limited resources is time consuming, stressful and difficult (Graham et al., 2016; Katz, Crean, Cerulli, \& Poleshuck, 2018).

Thus, these discourses disempower women from providing responses to the very problems that researchers are seeking to answer. Research is increasingly dominant in health and healthcare practices but, if the research and the wider discourses which surround its use are developed without reference to women's lived realities, it can silence women and give an inaccurate portrayal of the context.

When we reflect further on this analysis, we detect an expectation that women will be compliant and will follow instructions and directives. Women's identity is subsumed by the pregnancy in the discourse. In contrast to the language of food security and empowerment, the analysis presents many points of conflict but is also a chance to reframe how health professionals and the general public view nutrition in pregnancy. There is much potential for non-government organisations, health professionals and academics to reframe this discourse, thus working to empower women and make their voices heard by focusing on the importance of food security for women and their families.

As health professionals, midwives can reframe the discussion around nutrition in pregnancy and advocate for a policy-based approach to effectively respond to the chronic and widespread concern of malnutrition in pregnancy. Midwives have a role to play in making heard less dominant narratives, alongside advocating 
for woman-centred, policy-based approaches towards nutrition, whereby the underlying drivers of poverty are actively addressed.

\section{CONCLUSION}

This paper argues that the current discourse around nutrition in pregnancy is not working to resolve a chronic public health concern. Pregnant women as citizens require effective government action in the form of accurate monitoring, political and social policy provision which responds to problems of food security, and empowerment to create transformative change. This approach views women as functioning citizens deserving of rights and of contributing to solutions, rather than as having the narrow identity of women as seen in the discourse who are expected to conform and to "walk the tightrope". As has been aptly put by these authors: "Nutrition public policy must be linked to broader strategies that respect and empower non-discriminatory and economically secure livelihoods for all women and girls, and all men and boys... nutrition policy must support and facilitate women's own plans - whether aligned to or separate from marketbased nutrition products - for their own, their families', and their communities' nutritional health" (Bellows \& de Lara, 2016, p.65).

\section{ACKNOWLEDGEMENTS AND CONFLICT OF INTEREST DISCLOSURE}

The first author undertook a CDA that contributed to the degree of Master in International Development (Raven, 2018). The project was examined externally and awarded a first class pass.

The authors declare that there are no conflicts of interest.

\section{Key messages}

- A prevailing discourse surrounding pregnant women's poor nutrition is one of individual deficit and/or lack of knowledge.

- Food security and empowerment analysis provides a chance to reframe how health professionals and the general public view nutrition in pregnancy.

- Midwives can reframe malnutrition in pregnancy discussions, advocating for woman-centred, policy-based approaches, whereby the underlying drivers of poverty are actively addressed.

\section{REFERENCES}

Auckland District Health Board National Women's Health. (2017). Eating Guidelines: Maternity Services - Eating Well During Pregnancy. Retrieved from http://nationalwomenshealth.adhb.govt.nz/services/ maternity/pregnancy-advice/eating-well

Australian Associated Press. (2011). Pregnancy Diet Overkill. Retrieved from https://www.stuff.co.nz/life-style/4906565/Pregnancy-diet-overkill Bellows, A.C., \& de Lara, M. (2016). Gender, nutrition, and the right to adequate food: Introducing two structural disconnects and the human rights processes necessary to address them. In A.C. Bellows, F.L.S.Valente, S. Lemke, \& M.D.N.B. de Lara (Eds.), Gender, Nutrition, and the Human Right to Adequate Food: Toward an Inclusive Framework (pp.58-107). New York: Routledge, Taylor \& Francis.

Blumfield, M.L., Hure, A.J., Macdonald-Wicks, L., Smith, R., $\&$ Collins, C.E. (2013). A systematic review and meta-analysis of micronutrient intakes during pregnancy in developed countries. Nutrition Reviews, 71(2), 118-132.
Boland, R., \& Gibbons, M. (2009). The cost of healthy eating for pregnant and breastfeeding women in Otago. New Zealand College of Midwives Journal, 41, 26-28.

Brody, A. (2015). Gender and Food Security: An Overview. Bridge Development \& Gender: Cutting Edge Programmes Series. Retrieved from https://opendocs.ids.ac.uk/opendocs/bitstream/ handle/123456789/5742/Gender\%20and\%20FS\%20In\%20Brief.pdf Broussard, N.H. (2019). What explains gender differences in food security? Food Policy, 83, 180-194.

Corderoy, A. (2017). Pregnant Women 'Mistaken' over Healthy Diet. Retrieved from https://i.stuff.co.nz/life-style/parenting/71150687/null Counties Manukau District Health Board. (2013). Antenatal Management of Obesity/Morbid Obesity. Auckland: Author.

Davies, P., Funder, J., Palmer, D., Sinn, J., Vickers, M., \& Wall, C. (2016). Early life nutrition and the opportunity to influence long-term health: an Australasian perspective. Journal of Developmental Origins of Health and Disease, 7(5), 440-448.

de Schutter, O. (2016). Foreword. In A.C. Bellows, L.S. Flavio \& S. Lemke (Eds.), Gender, Nutrition, and the Human Right to Adequate Food (pp. xix-xxiv). New York: Taylor and Francis.

Dodds, A., \& Chamberlain, K. (2017). The problematic messages of nutritional discourse: A case-based critical media analysis. Appetite, 108, 42-50.

Essentialbaby.com.au. (2015). 10 Foods for a Healthier Pregnancy. Retrieved from http://www.stuff.co.nz/life-style/parenting/pregnancy/ expecting/69088493/10-foods-for-a-healthier-pregnancy

Fairclough, N. (1995). Critical Discourse Analysis: The Critical Study of Language. London: Longman.

Fairclough, N. (2003). Analysing Discourse: Textual Analysis for Social Research. New York: Routledge.

Ferguson, E.L., Morison, I.M., Faed, J.M., Parnell, W.R., McKenzie, J., Wilson, N.C., \& Russell, D.G. (2001). Dietary iron intakes and biochemical iron status of 15-49 year old women in New Zealand: Is there a cause for concern? The New Zealand Medical Journal, 114(1128), 134-138.

Food and Agriculture Organization of the United Nations. (1996). Rome Declaration on World Food Security and World Food Summit Plan of Action. Paper presented at the World Food Summit, Rome, Italy. Retrieved from http://www.fao.org/docrep/003/w3613e/w3613e00.htm Food and Agriculture Organization of the United Nations. (2008). Introduction to the Basic Concepts of Food Security. Rome, Italy: Author. Retrieved from http://www.fao.org/docrep/013/al936e/al936e00.pdf

Food and Agriculture Organization of the United Nations, International Fund for Agricultural Development, United Nations Children's Fund and World Health Organisation (2017). The State of Food Security and Nutrition in the World: Building Resilience for Peace and Food Insecurity. Rome, Italy: Author. Retrieved from http://www.fao.org/3/a-i7695e.pdf Food Standards Australia and New Zealand. (2016). Pregnancy and Healthy Eating. Retrieved from http://www.foodstandards.govt.nz/ consumer/generalissues/pregnancy/Pages/default.aspx

Gibson, R.S., Heath, A.L.M., \& Ferguson, E.L. (2002). Risk of suboptimal iron and zinc nutriture among adolescent girls in Australia and New Zealand: Causes, consequences, and solutions. Asia Pacific Journal of Clinical Nutrition, 11, S543-S552.

Graham, R., \& Jackson, K. (2017). No, poor New Zealand families can't just grow their own vegetables. The Spinoff. Retrieved from https:// thespinoff.co.nz/parenting/09-08-2017/no-poor-new-zealand-familiescant-just-grow-their-own-vegetables/

Graham, R., Stolte, O., Hodgetts, D., \& Chamberlain, K. (2016). Nutritionism and the construction of 'poor choices' in families facing food insecurity. Journal of Health Psychology, 23, 14.

Greig, A.J., Patterson, A.J., Collins, C.E., \& Chalmers, K.A. (2013). Iron deficiency, cognition, mental health and fatigue in women of childbearing age: A systematic review. Journal of Nutritional Science, 2, e14.

Growing Up in New Zealand. (2014). Nutrition and Physical Activity during Pregnancy: Evidence from Growing $U_{p}$ in New Zealand. Retrieved from http://www.superu.govt.nz/publication/nutrition-and-physicalactivity-during-pregnancy

Hartley, J. (2017). Overeating in Pregnancy: No More 'Eating for Two'. Retrieved from http://www.stuff.co.nz/lifestyle/parenting/pregnancy/ expecting/68407024/overeating-in-pregnancy-no-more-eating-for-two Headey, D., Oliver, E., \& Trinh Tan, J. (2014). Shocks to the System: Monitoring Food Security in a Volatile World. In R.G. Jha, R. Gaiha \& A.B. Deolalikar (Eds.), Handbook on Food: Demand, Supply, Sustainability and Security (pp.41-71). Cheltenham: Edward Elgar. 
Horton, S., \& Ross, J. (2003). The economics of iron deficiency. Food Policy, 28(1), 51-75.

James, P., \& Rigby, N. (2012). The challenge of the chronic diseases epidemic for science and society. In J. Mann \& S.A. Truswell (Eds.), Essentials of Human Nutrition (4th ed., pp. 287-300). Oxford: Oxford University Press.

Janks, H. (1997). Critical discourse analysis as a research tool. Discourse: Studies in the Cultural Politics of Education, 18(3), 329-342.

Jha, R., Gaiha, R., \& Deolalikar, A. B. (2014). Overview: Handbook on Food: Demand, Supply, Sustainability and Security. In R. G. Jha, R. \& A. B. Deolalikar (Eds.), Handbook on Food: Demand, Supply, Sustainability and Security (pp.1-21). Cheltenham: Edward Elgar.

Kabeer, N. (2010). Women's empowerment, development interventions, and management of information flows. Special Issue: People-centred M\&E: Aligning Incentives So Agriculture Does More to Reduce Hunger, IDS Bulletin, 41(6), 105-113.

Katz, J., Crean, H.F., Cerulli, C., \& Poleshuck, E.L. (2018). Maternal hardship and mental health symptoms among a predominantly low income sample of pregnant women seeking prenatal care. Maternal and Child Health Journal, 22, 1360-1367.

Kimura, A.H. (2013). Hidden Hunger: Gender and the Politics of Smarter Foods: Ithaca: Cornell University Press.

Locke, T. (2004). Critical Discourse Analysis: New York: Continuum.

Martin, M.A., \& Lippert, A.M. (2012). Feeding her children, but risking her health: The intersection of gender, household food insecurity and obesity. Social Science \& Medicine, 74, 1754-1764.

Ministry of Health. (2008a). A Portrait of Health. Key results of the 2006/07 New Zealand Health Survey. Wellington: Author.

Ministry of Health. (2008b). Food and Nutrition Guidelines for Healthy Pregnant and Breastfeeding Women: A Background Paper. Wellington: Author.

Ministry of Health. (2012). A Focus on Nutrition: Key Findings From the 2008/09 NZ Adult Nutrition Survey. Wellington: Author.

Ministry of Health. (2017). Eating for Healthy Pregnant Women/Ngā Kai Totika mā te Wahine Hapū. Retrieved from https://www.healthed.govt. nz/system/files/resource-files/HE1805_Healthy\%20for\%20healthy\%20 pregnant $\% 20$ women.pdf

Morton, S., Grant, C., Wall, C., Carr, P., Bandara, D., Schmidt, J., \& Camargo, C. (2014). Adherence to nutritional guidelines in pregnancy: Evidence from the Growing Up in New Zealand birth cohort study. Public Health Nutrition, 17(9), 1-11.

Nakhle, A. (2015). Pregnancy 'Don'ts' - Are They That Different Around the World? Retrieved from http://www.stuff.co.nz/lifestyle/parenting/ pregnancy/68914590/pregnancy-donts--are-they-that-different-aroundthe-world

National Council of Women of New Zealand. (2019). Gender Dashboard Data Stories. Retrieved from https://genderequal.nz/datastories/not-justgender-pay-gap/)

Okesene-Gafa, K., Chelimo, C., Chua, S., Henning, M., \& McCowan, L. (2016). Knowledge and beliefs about nutrition and physical activity during pregnancy in women from South Auckland region, New Zealand. The Australian \& New Zealand Journal of Obstetrics \& Gynaecology, 56(5), 471-483. O'Leary, Z. (2009). The Essential Guide to Doing Your Research Project. London: Sage.

Papan, A.S., \& Clow, B. (2015). The food insecurity-obesity paradox as a vicious cycle for women: Inequalities and health. Gender \& Development, 23(2), 299-317.

Parnell, W.R. (2012). Nutritional consequences of poverty and food insecurity in developed countries. In J. Mann \& S.A. Truswell (Eds.), Essentials of Human Nutrition (4th ed., pp.645-653). Oxford: Oxford University Press.

Paterson, H., Hay-Smith, E.J.C., \& Treharne, G.J. (2016). Women's experiences of changes in eating during pregnancy: A qualitative study in Dunedin, New Zealand. New Zealand College of Midwives Journal, 52, 5-11.

Pearce, J.R., Richardson, E.A., Mitchell, R.J., \& Short, N.K. (2011). Environmental justice and health: A study of multiple environmental deprivation and geographical inequalities in health in New Zealand. Social Science \& Medicine, 73(3), 410-420.

Pollard, C.M., \& Booth, S.M. (2019). Food insecurity and hunger in rich countries - It is time for action against inequality. Environmental Research and Public Health, 16, 1804.

Pullon, S., Ballantyne, A., Macdonald, L., Barthow, C., Wickens, K., \& Crane, J. (2019). Daily decision-making about food during pregnancy: A New Zealand Study. Health Promotion International, 34, 469-478.
Raven, B. (2018). 'Walking the Tightrope' Pregnant Women \& Malnutrition in Aotearoa: How the Sustainable Development Goals 2 \& 5 Reframe the Current Discourse (Master's thesis in International Development). Palmerston North: Massey University.

Schlichting, D., Hashemi, L., \& Grant, C. (2019). Infant food security in New Zealand: A multidimensional index developed from cohort data. Internationl Journal of Environmental Research and Public Health, 16(2), E283.

Shetty, P. (2008). Malnutrition and nutrition policies in developing countries. In V. Desai \& R. Potter (Eds.), The Companion to Development Studies (2nd ed., pp.399-402). London: Hodder Education. Smith, M., \& Signal, L. (2009). Global influences on milk purchasing in New Zealand - implications for health and inequalities. Globalization and Health, 5(1), 1-13.

Tasker, B. (2017). Half of Mums-to-be Gain too much Weight. Retrieved from http://www.stuff.co.nz/life-style/parenting/pregnancy/93403337/ half-of-mumstobe-gain-too-much-weight

Tiffin, R. (2014). Food Security. In V. Desai \& R.B. Potter (Eds.), The Companion to Development Studies, (3rd ed., pp.235-244). Abingdon, Oxfordshire: Routledge.

Wall, C.R., Gammon, C.S., Bandara, D.K., Grant, C.C., Atatoa Carr, P.E., \& Morton, S.M.B. (2016). Dietary patterns in pregnancy in New Zealand - influence of maternal socio-demographic, health and lifestyle factors. Nutrients, 8(5), p.E300.

Weiss, G., \& Wodak, R. (2002). Introduction: theory, interdisciplinarity and critical discourse analysis. In G. Weiss \& R. Wodak (Eds.), Critical Discourse Analysis: Theory and Interdisciplinarity (pp.1-34): Basingstoke, Hampshire; New York: Palgrave Macmillan.

Wendelbo, M. (2018). Hidden hunger affects nearly 2 billion worldwide - are solutions in plain sight? The Conversation. Retrieved from https:// theconversation.com/hidden-hunger-affects-nearly-2-billion-worldwideare-solutions-in-plain-sight-104740

World Health Organization (2006). Guidelines on Food Fortification with Micronutrients. Retrieved from https://www.who.int/nutrition/ publications/guide_food_fortification_micronutrients.pdf

World Health Organization. (2008). Anaemia as a Public Health Problem by Country: Pregnant women. Retrieved from http://www.who.int/vmnis/ anaemia/prevalence/summary/PW_anaemia.pdf?

Yin, S., Dixon, L., Paterson, H., \& Campbell, N. (2014). New Zealand LMC midwives' approaches to discussing nutrition, activity and weight gain during pregnancy. New Zealand College of Midwives Journal, 50, 24-29.

\section{Accepted for Publication September 2019}

Raven, B., \& Stewart-Withers, R. (2019). Using critical discourse analysis and the concept of food security to understand pregnant women's nutrition in Aotearoa/New Zealand. New Zealand College of Midwives Journal, 55, 35-43.

https://doi.org/10.12784/nzcomjnl55.2019.5.35-43 